\title{
ACCURACY OF DETERMINED S-N CURVE BY SELECTED MODELS
}

\author{
PRZEMYSEAW STRZELECKI \\ University of Technology and Life Sciences, Faculty of Mechanical Engineering, Bydgoszcz, Poland \\ e-mail: p.strzelecki@utp.edu.pl
}

\begin{abstract}
The study shows models defining the relationship between the fatigue life and the stress amplitude. The first models have been developed at the beginning of the 20th century; however, new models are still being developed. The author decided to compare the most commonly used model, i.e. a linear regression model and the two models discussed in ISO-12107. The comparison also included some recently developed models, i.e. Strohmeyer, Basenaire, Castillo et al., Kohout and Vechet, Leonetti et al., and Pasual and Meeker model, including its modified version. The fatigue data for S355J2+C and AISI 1045 steel were used for the comparison. The best estimate of the fatigue life was obtained by using the modified Pasual and Meeker model.
\end{abstract}

Keywords: S-N curve, high-cycle fatigue, steel, fatigue design, data analysis

\section{Introduction}

The first fatigue tests were carried out in the 19th century by Wöhler. Test results are generally presented as a simple regression as proposed by Basquin in 1910 (Schütz, 1996). However, new models defining the relationship between the fatigue life and the load in a high-cycle fatigue range are still being developed. The Basquin suggestion is usually expressed as (ISO-12107, 2012)

$$
\log N=m \log \left(S_{a}\right)+a
$$

where $N$ is the fatigue life, $S_{a}$ is the stress amplitude, $m$ and $a$ are regression line coefficients, i.e. the direction coefficient and the intercept coefficient, respectively. It is commonly used due to its simplicity and a low number of coefficients. An example use of the model can be found in Skibicki (2007). Tests showed, however, that a straight line does not necessary reflect changes in the fatigue life due to load, in particular, in the fatigue limit region. Thus, other models defining those effects were developed. ISO-12107 (2012) suggests the Strohmeyer (Eq. (1.2)) and the Basenaire (Eq. (1.3)) models, expressed as follows

$$
\log N=m \log \left(S_{a}-E\right)+a
$$

and

$$
\log N=\log A-\log (S-E)-\left(\frac{S-E}{B}\right)^{C}
$$

where $E$ is the fatigue limit, $A, B$ and $C$ are model parameters.

Several other models are available. The models with detailed description can be found in Castillo and Fernández-Canteli (2009), Weibull (1961) and Szala and Ligaj (2011). The analysed models can be placed into one of three groups. The first group includes models describing a limited fatigue life range only. Those models describe materials that do not show a fatigue 
limit, i.e. aluminium and titanium alloys, etc. The material characteristics were discussed in Tomaszewski and Sempruch (2017), where the scatter of the test results for $10^{6}$ cycles did not exceed the scatter for a shorter fatigue life. The next group includes relationships defining the high-cycle region and the fatigue limit. The models best define the characteristics of materials similar to steel and are most often used in the design of machine components, e.g. hammer mill described in Bochat et al. (2015). The last group describes the complete characteristic, i.e. the low-cycle region, the high-cycle region and the fatigue limit. Those tests can be found in Szala and Ligaj (2012). The first group also includes Eq. (1.1). The second group includes the Strohmeyer model, and the last group includes the Basnaire model.

The study compares the models recommended in ISO-12107 (2012) and the models presented recently in the literature, i.e. in the last three decades. Two steel grades were compared, i.e. S355J2+C and AISI 1045. A similar verification was carried out by Kurek et al. (2014), however that study did not cover the most recent methods.

The first model selected by the author was the relationship presented by Castillo et al. (1985), which can be expressed as

$$
\log \frac{N}{N_{0}}=\frac{\lambda+\delta(-\ln (1-p))^{\frac{1}{\beta}}}{\log \frac{S_{a}}{S_{0}}}
$$

where $\beta, \delta$ and $\lambda$ are the Weibull distribution parameters, i.e. shape, scale and location parameter for zero probability, $N_{0}$ is the limit value for the number of cycles and $S_{0}$ is the limit value for the stress amplitude. The model can also be expressed as a cumulative Weibull distribution function

$$
F\left(\log N, \log S_{a}\right)=1-\exp \left[-\left(\frac{\left(\log N-\log N_{0}\right)\left(\log S_{a}-\log S_{0}\right)-\lambda}{\delta}\right)^{\beta}\right]
$$

Another model selected by the author is a model developed by Pascual and Meeker (1999), expressed as follows

$$
\log N=\Phi^{-1}\left(\frac{q}{\Phi\left(\frac{S_{a}-E}{\sigma_{E}}\right)}, m \log \left(S_{a}\right)+a, \sigma_{N}\right)
$$

where $\Phi$ is a normal distribution function, $\Phi^{-1}$ is the invert of the normal distribution function, $\sigma_{E}$ is the standard deviation for the fatigue limit and $\sigma_{N}$ is the standard deviation for the limited fatigue life. Castillo and Fernández-Canteli (2009) included a remark that this model is identical to the model suggested by Strohmeyer, which may lead to false conclusions. The form of equation (1.6) is the result of a transformation of equation (1.2) by introducing two probability distributions instead of one. The first distribution applies to the fatigue life in the high-cycle range and the second distribution applies to the fatigue limit. Since in the Strohmeyer model the lowest stress amplitude must be higher than $E$, the value cannot be considered to be a fatigue limit, which is not the case in the Pascual and Meeker model.

The comparison also included the Kohout and Vechet (2001) model, expressed as follows

$$
\log S_{a}=\log S_{\infty}+\log \left(\frac{N+B}{N+C}\right)^{b}
$$

where $B$ and $C$ are parameters determining the fatigue life at the point of inflection in the low and high-cycle range, whereas $b$ is the reciprocal of the direction coefficient from Eq. (1.1). The relationship combines the linear regression from Eq. (1.1) and two asymptotes corresponding to the tensile strength and the fatigue limit. 
A new model has recently been presented by Leonetti et al. (2017)

$$
\log N=\beta_{0}+\beta_{1} \log S_{a}-p \log \left(1-\frac{E}{S_{a}}\right)
$$

where $p$ is a parameter corresponding to curvature of the transition curve from the limited fatigue life range to the fatigue limit range.

The last compared model is modified equation (1.6) proposed by Strzelecki and Tomaszewski (2016), expressed as follows

$$
P_{W}\left(N<N_{i}\right)=F_{W}\left(\log N_{i}\right) F_{W}\left(S_{i}\right)=q
$$

where $F_{W}$ is a 2-parameter and 3-parameter Weibull distribution function expressed as

$$
F_{W}\left(\log N_{i}\right)=1-\exp \left[-\left(\frac{x-\zeta(S)}{\beta(S)}\right)^{\alpha_{\nu}}\right] \quad F_{W}\left(S_{i}\right)=1-\exp \left[-\left(\frac{x}{\beta_{z}}\right)^{\alpha_{z}}\right]
$$

where $\alpha_{\nu}$ is a shape parameter for the fatigue life, $\beta(S)$ is a scale parameter depending on the stress amplitude and expressed as $n \log (S)+d, \zeta(S)$ is a location parameter depending on the stress amplitude and expressed as $l \log (S)+e, \alpha_{z}$ is a shape parameter for the fatigue limit and $\beta_{z}$ is a scale parameter for the fatigue limit.

It is the Pascual and Meeker model modified by replacing the normal distribution with the 3 -parameter Weibull distribution for the limited fatigue life range and with the 2-parameter distribution for the fatigue limit. Also, introduction of the scale and the location parameter variability for the fatigue life distribution (Eq. (1.10)) makes the description of the fatigue life scatter dependent on the load level.

\section{Experimental methods and results}

The fatigue data for constructional steel S355J2+C were used in the comparison. The material was purchased as a $10 \mathrm{~mm}$ dia. drawn rod. The specimens were prepared as illustrated in Fig. 1. The tests were performed using the rotating bending test station, verified in Strzelecki and Sempruch (2012). The load frequency used was $28.5 \mathrm{~Hz}$. The tests were planned in accordance with the requirements laid down in ISO-12107 (2012). Out of 40 tests, 15 tests were used for the staircase method to determine the fatigue limit. Figure 2 a shows the test results. Table 1 shows the mechanical properties of the material.

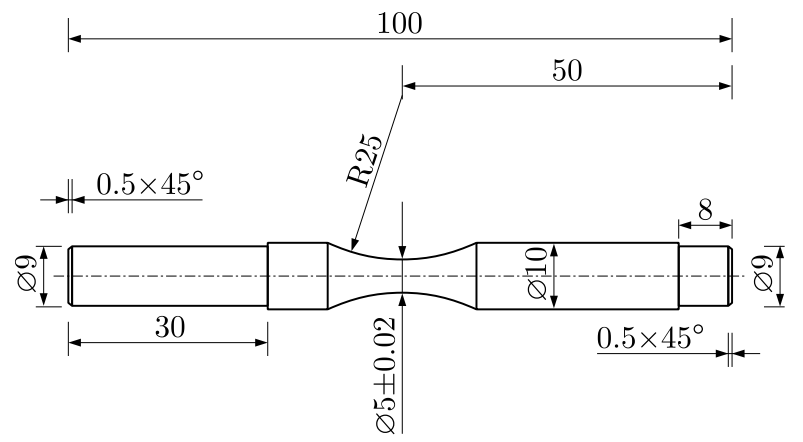

Fig. 1. Specimen shape and dimensions

AIS 1045 medium-carbon steel data available in the literature were used to validate the comparison results. The test results for this material are available in Aviles et al. (2013). The tests were carried out using Zwick-Roell UBM 200tc rotating bending machine. The load frequency used was $33.3 \mathrm{~Hz}$. A total of 55 specimens were used, 20 of which were used in the staircase method. Figure 2b shows the results. 
(a)

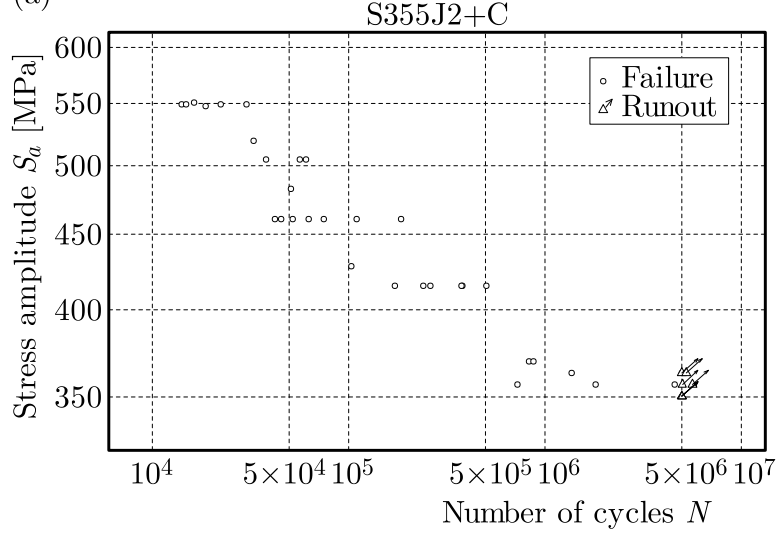

(b)

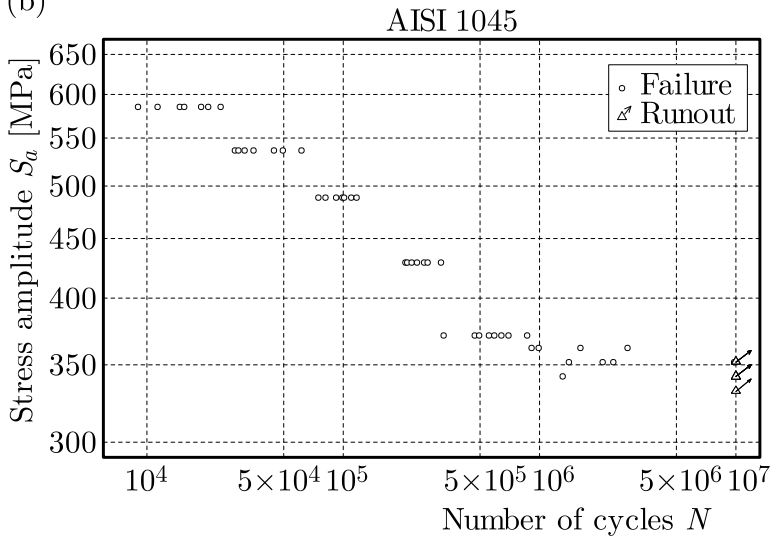

Fig. 2. Experimental results for steel: (a) S355J2+C and (b) AISI 1045

Table 1. Mechanical properties of steel S355J2+C

\begin{tabular}{|c|c|c|c|}
\hline$S_{u}[\mathrm{MPa}]$ & $S_{y}[\mathrm{MPa}]$ & $A[\%]$ & $Z[\%]$ \\
\hline \hline 809 & 684 & 12.2 & 63.8 \\
\hline
\end{tabular}

\section{Comparison of models and discussion}

The model parameters were determined using the maximum likelihood estimation. The following likelihood function was used for the Strohmeyer, Bastenaire, Kohout and Vechet models

$$
L(N, S ; \theta)=\prod_{i=1}^{n} \phi\left(\frac{\log N_{i}-\nu_{S_{a}}}{\sigma_{\nu}}\right)
$$

where $\nu_{S_{a}}$ is a relationship proposed by the model. The following function was used for the other models

$$
L(N, S ; \theta)=\prod_{i=1}^{n}\left[g\left(\nu_{S_{a}}\right)\right]^{\delta_{i}}\left[1-G\left(\nu_{S_{a}}\right)\right]^{1-\delta_{i}}
$$

where $g$ is a probability distribution used by the model, $G$ is a probability distribution function used by the model and $\delta_{i}$ is a value equal to 1 or 0 for cracked and runout specimens, respectively. Detailed information on the estimation method based on those functions can be found in Pascual and Meeker (1999), Pollak and Palazotto (2009), Ling and Pan (1997), Strzelecki et al. (2016), Sarkani et al. (2007) and Fouchereau et al. (2014). For the models included in the group of characteristics defining a complete S-N curve, i.e. the Bastenaire and Kohout and Vechet models, the tensile test results were also used in the estimation.

Figures 3 and 4 show the estimated characteristics.

An error between the obtained characteristics and the experimental fatigue life was determined to compare the models. The following formula was used

$$
B_{l}=\log N_{e}-\log N_{p}
$$

where $N_{e}$ is the experimental fatigue life, $N_{p}$ is the fatigue life estimated using each model.

This method to calculate the error of fatigue life estimation was presented in Strzelecki and Sempruch (2016). The difference consists in changing the error calculation range from the constant fatigue life determined experimentally to the entire range of the results. Figures 5 and 6 show the calculation results as histograms. 


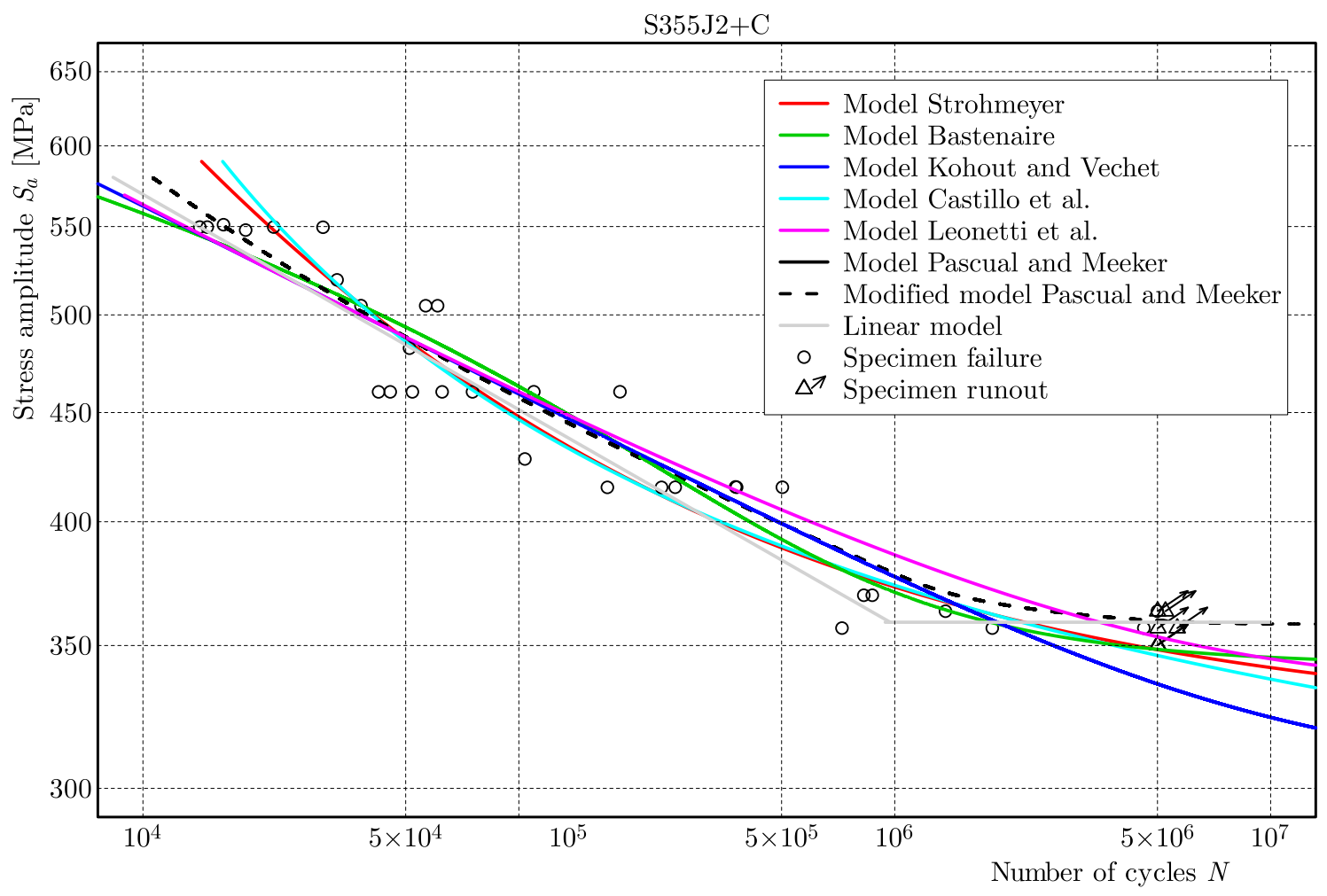

Fig. 3. S-N curves for different models for steel S355J2+C

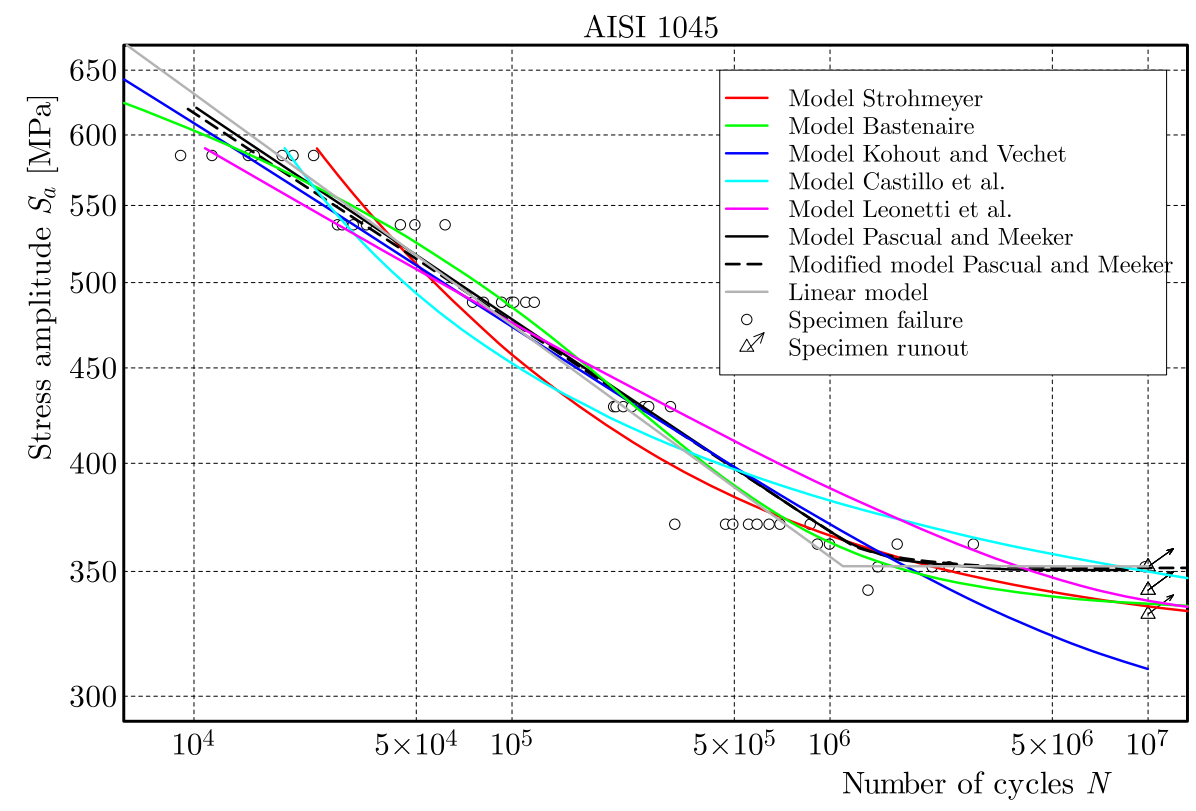

Fig. 4. S-N curves for different models for steel AISI 1045

The parameters of the Weibull distribution defining the fatigue life estimation error for different models were also estimated. Tables 2 and 3 show the calculation results. Since the distribution must include a variable larger than zero, a value of 10 was added to the error value $B_{l}$. This distribution was chosen, since some of the histograms are clearly skewed, e.g. Fig. 5a, Fig. 5d and Fig. 6c. Using a normal distribution in those cases, the Shapiro-Wilk test gave the basis to dismiss the hypothesis stating that the distribution of the errors is normal. Figures $5 \mathrm{i}$ and $6 \mathrm{i}$ show the Weibull distributions. To validate the use of this distribution, the Chi-square $\left(\chi^{2}\right)$ test was carried out with the results shown in Tables 2 and 3. 
(a)

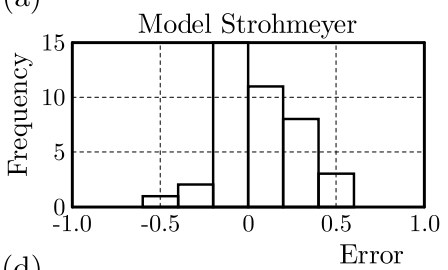

(d)

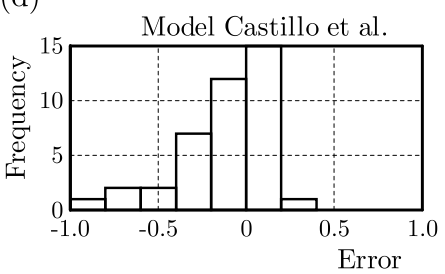

(g) Modified model Pascual

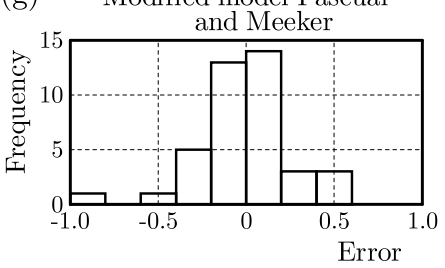

(b)

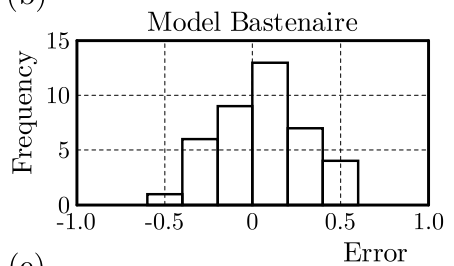

(e)

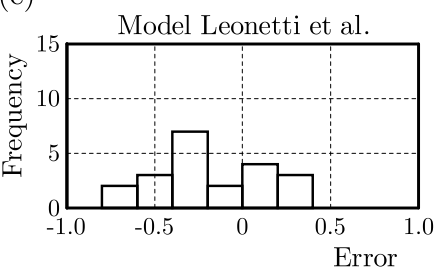

(h)

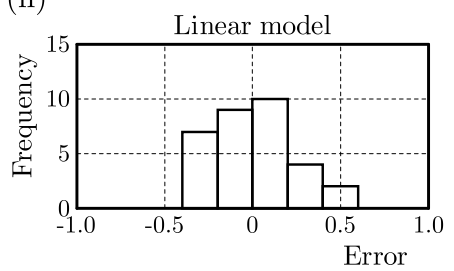

(c)

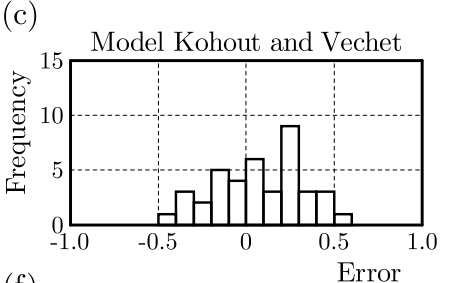

(f)

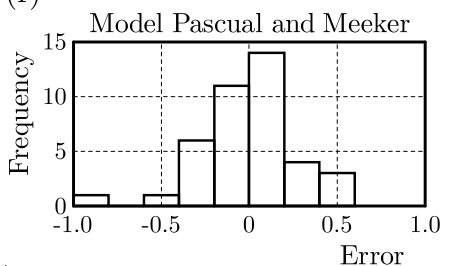

(i)

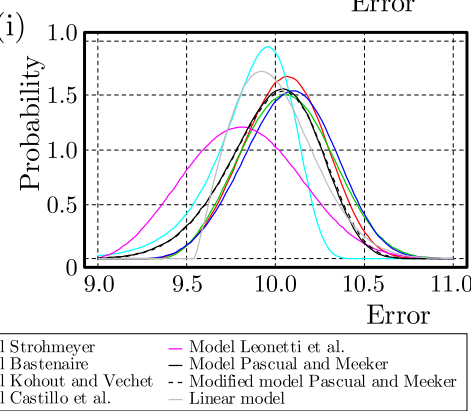

Fig. 5. Histogram of the error for different models for steel S355J2+C

(a)

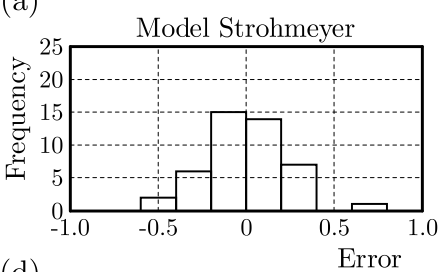

(d)

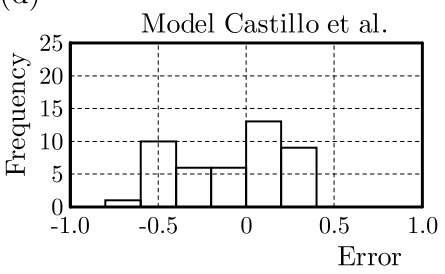

(g) Modified model Pascual

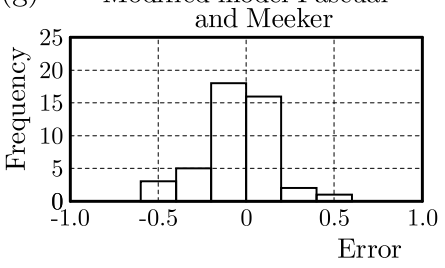

(b)

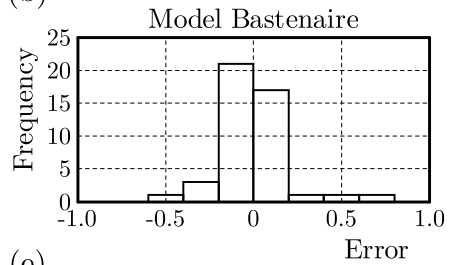

(e)

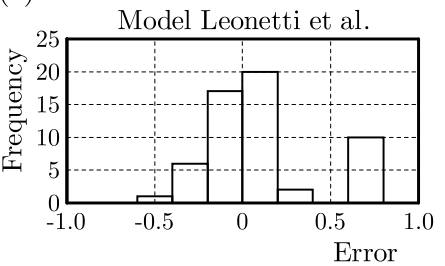

(h)

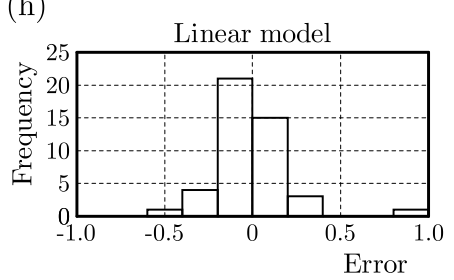

(c)

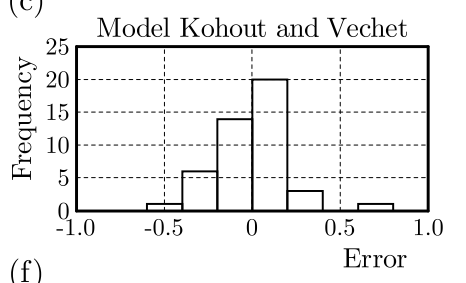

(f)

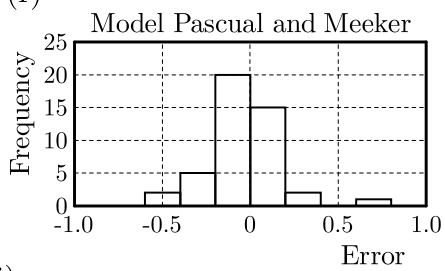

(i)

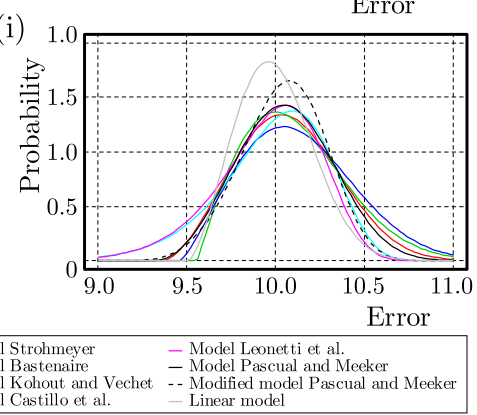

Fig. 6. Histogram of the error for different models for steel AISI 1045

For all $\chi^{2}$ tests, the obtained $p$-value was higher or equal to 0.05 , indicating that the hypothesis was correct and the errors were characterized by the Weibull distribution (Table 4). Low $p$-values were usually observed in histograms with an empty interval. In those cases, the number of classes in the $\chi^{2}$ test was reduced. 
Table 2. Quantitative verification of the Weibull distribution for the estimated error for S355J2+C steel

\begin{tabular}{|l|c|c|c|c|}
\hline \multirow{2}{*}{ Method } & \multicolumn{2}{|c|}{ Weibull distribution values } & p-values obtained \\
\cline { 2 - 4 } & Shape & Scale & Location & by the $\chi^{2}$ test \\
\hline \hline Strohmeyer & 3.92 & 0.89 & 9.23 & 0.06 \\
\hline Basenaire & 3.16 & 0.82 & 9.33 & 0.22 \\
\hline Kohout and Vechet & 3.86 & 0.96 & 9.21 & 0.24 \\
\hline Castillo et al. & 42.83 & 8.10 & 1.86 & 0.29 \\
\hline Leonetti et al. & 3.02 & 0.98 & 8.95 & 0.39 \\
\hline Pascual and Meeker & 6.30 & 1.51 & 8.57 & 0.08 \\
\hline Modified model Pascual and Meeker & 5.87 & 1.43 & 8.66 & 0.05 \\
\hline Linear model (Basquin) & 2.09 & 0.51 & 9.54 & 0.11 \\
\hline
\end{tabular}

Table 3. Quantitative verification of the Weibull distribution for the estimated error for AISI 1045 steel

\begin{tabular}{|l|c|c|c|c|}
\hline \multirow{2}{*}{ Method } & \multicolumn{2}{|c|}{ Weibull distribution values } & p-values obtained \\
\cline { 2 - 4 } & Shape & Scale & Location & by $\chi^{2}$ test \\
\hline \hline Strohmeyer & 2.69 & 0.80 & 9.36 & 0.07 \\
\hline Basenaire & 1.99 & 0.63 & 9.56 & 0.26 \\
\hline Kohout and Vechet & 2.25 & 0.76 & 9.46 & 0.23 \\
\hline Castillo et al. & 11.92 & 3.20 & 6.91 & 0.07 \\
\hline Leonetti et al. & 10.84 & 2.81 & 7.27 & 0.07 \\
\hline Pascual and Meeker & 3.06 & 0.84 & 9.31 & 0.05 \\
\hline Modified model Pascual and Meeker & 4.47 & 1.02 & 9.11 & 0.09 \\
\hline Linear model (Basquin) - cycles less $10^{6}$ & 2.50 & 0.55 & 9.51 & 0.05 \\
\hline
\end{tabular}

Table 4. Mean and standard deviation from the Weibull distribution for different models

\begin{tabular}{|l|c|c|c|c|}
\hline \multirow{2}{*}{ Method } & \multicolumn{2}{|c|}{ Mean value } & \multicolumn{2}{c|}{ Standard deviation } \\
\cline { 2 - 5 } & S355J2+C & AISI 1045 & S355J2+C & AISI 1045 \\
\hline \hline Strohmeyer & 0.046 & 0.071 & 0.231 & 0.285 \\
\hline Basenaire & 0.065 & 0.113 & 0.254 & 0.292 \\
\hline Kohout and Vechet & 0.079 & 0.133 & 0.251 & 0.316 \\
\hline Castillo et al. & -0.144 & -0.018 & 0.235 & 0.312 \\
\hline Leonetti et al. & -0.179 & -0.046 & 0.316 & 0.299 \\
\hline Pascual and Meeker & -0.024 & 0.057 & 0.260 & 0.267 \\
\hline Modified model Pascual and Meeker & -0.017 & 0.041 & 0.261 & 0.237 \\
\hline Linear model (Basquin) - cycles less $10^{6}$ & -0.001 & -0.003 & 0.228 & 0.210 \\
\hline
\end{tabular}

Based on those distributions, the average values and the standard deviation were calculated. Table 5 shows the results. The average value was reduced by 10 .

The lowest fatigue life estimation error was obtained for the linear model (Basquin), however, the fatigue life was compared to $10^{6}$ cycles only. Thus, this model should not be included in the comparison. The comparison of other models shows that the average error closest to zero can be observed in the modified Pascual and Meeker model for both materials. The lowest standard deviation for S355J2+C steel can be observed in the Strohmeyer model, and in the modified Pascual and Meeker model for AISI 1045 material. 
Table 5. Coefficient of determination for verified models

\begin{tabular}{|l|c|c|}
\hline \multirow{2}{*}{ Method } & \multicolumn{2}{|c|}{ Material } \\
\cline { 2 - 3 } & S355J2+C & AISI 1045 \\
\hline \hline Strohmeyer & 0.933 & 0.908 \\
\hline Bastenaire & 0.913 & 0.893 \\
\hline Kohout and Vechet & 0.910 & 0.872 \\
\hline Castillo et al. & 0.894 & 0.882 \\
\hline Leonetti et al. & 0.845 & 0.898 \\
\hline Pascual and Meeker & 0.920 & 0.926 \\
\hline Modified Pascual and Meeker & 0.921 & 0.941 \\
\hline Linear (Basquin) - cycles less $10^{6}$ & 0.898 & 0.927 \\
\hline
\end{tabular}

The coefficients of determination were also calculated for each model for comparison. The following formula was used (ISO-12107, 2012)

$$
R^{2}=\frac{\sum_{i=1}^{n}\left(\log \widehat{N}_{i}-\log \bar{N}\right)^{2}}{\sum_{i=1}^{n}\left(\log N_{i}-\log \bar{N}\right)^{2}}
$$

where $\widehat{N}_{i}$ is a value estimated by the model, $\bar{N}$ is an average fatigue life for all observations.

The comparison of the coefficients of determination shows that for S355J2+C, the best results could be obtained by using the Strohmeyer model and the modified Pascual and Meeker model. The difference between the original Pascual and Meeker model and the modified model was negligible. For AISI 1045, the best result could be obtained by using the modified Pascual and Meeker model and the original model. ISO-12107 (2012) states that the coefficient value of 0.9 and higher indicates that the regression matching is good. Based on the results, the Castillo et $a l$. and the Leonetti et al. models were identified as not meeting this condition for both materials. Also, the condition was not met by the Kohout and Vachet model for AISI 1045 material.

\section{Summary and conclusions}

A comparison of the selected S-N curve models shows that the Castillo et al. and the Leonetti et al. models yield the worst results. In the case of the latter method, a modification of the Strohmeyer model did not improve the accuracy of the fatigue limit estimation and had the opposite effect. An increase in the number of parameters made the estimation even more difficult. Based on the Castillo et al. model analysis, using a 2-parameter Weibull distribution instead of a 3-parameter distribution might facilitate the estimation of the model parameters. Finally, there was a question of the applicability of the $\lambda$ location parameter, since two parameters i.e. $N_{0}$ and $S_{0}$, corresponding to the zero probability of the fatigue life and the stress amplitude, respectively were already used.

The comparative analysis of the models describing a complete S-N curve (Bastenaire, Kohout and Vechet) showed that the estimation error for those models was higher compared to the models describing the high-cycle fatigue and the fatigue limit. It may be due to using the data from a fatigue life range between $10^{4}$ and $10^{7}$ cycles. Thus, the models must only be used if the $\mathrm{S}-\mathrm{N}$ curve was used to predict the fatigue life in the low and high-cycle range.

The modified Pascual and Meeker model and the original Pascual and Meeker model yielded the best results. However, due to its simplicity and a similar estimation error compared to the modified model, it was recommended to use the original Pascual and Meeker model. The original 
Pascual and Meeker model should not be used for calculations at low probability, i.e. below $5 \%$ due to using normal distribution, which is not recommended in accordance with ASTM E-739-91 (2006).

The modified Pascual and Meeker model uses 7 coefficients, i.e. 4 more coefficients than the simplest model. Equation (1.1) has two coefficients; however, using the normal distribution to determine the fatigue life also allows one to determine the standard deviation. These parameters allowed one to estimate the fatigue life with a higher accuracy. It is also possible to produce reliable S-N curves for low failure probability, even below 5\%, as discussed in Strzelecki and Tomaszewski (2016). A theoretical fatigue life at which no failure will occur can also be determined.

\section{References}

1. ASTM E-739-91, 2006, Standard Practice for Statistical Analysis of Linear or Linearized Stress-Life $(S-N)$ and Strain-Life $(\varepsilon-N)$ Fatigue Data

2. Aviles R., Albizuri J., Rodriguez A., Lopez De Lacalle L.N., 2013, Influence of low-plasticity ball burnishing on the high-cycle fatigue strength of medium carbon AISI 1045 steel, International Journal of Fatigue, 55, 230-244, DOI: 10.1016/j.ijfatigue.2013.06.024

3. Bochat A., Wesolowski L., Zastempowski M., 2015, A comparative study of new and traditional designs of a hammer mill, Transactions of the ASABE, 58, 3, 585-596, DOI: $10.13031 /$ trans. 58.10691

4. Castillo E., Canteli A.F., Esslinger V., Thurlimann B., 1985, Statistical model for fatigue analysis of wires, strands and cables, IABSE Proceedings, 1-40

5. Castillo, E., Fernández-Canteli, A., 2009, A Unified Statistical Methodology for Modeling Fatigue Damage, Springer, DOI: 10.1007/978-1-4020-9182-7

6. Fouchereau R., Celeux G., Pamphile P., 2014, Probabilistic modeling of S-N curves, International Journal of Fatigue, 68, 217-223, DOI: 10.1016/j.ijfatigue.2014.04.015

7. ISO-12107, 2012, Metallic materials - fatigue testing - statistical planning and analysis of data, Geneva

8. Kohout J., Veсhet S., 2001, A new function for fatigue curves characterization and its multiple merits, International Journal of Fatigue, 23, 2, 175-183, DOI: 10.1016/S0142-1123(00)00082-7

9. Kurek M., Lagoda T., Katzy D., 2014. Comparison of fatigue characteristics of some selected materials, Materials Testing, 56, 2, 92-95, DOI: 10.3139/120.110529

10. Leonetti D., Maljaars J., Snijder H.H., 2017, Fitting fatigue test data with a novel S-N curve using frequentist and Bayesian inference, International Journal of Fatigue, 105, 128-143, DOI: $10.1016 /$ j.ijfatigue.2017.08.024

11. Ling J., PAN J., 1997, A maximum likelihood method for estimating P-S-N curves, International Journal of Fatigue, 19, 5, 415-419, DOI: 10.1016/S0142-1123(97)00037-6

12. Pascual F.G., Meeker W.Q., 1999, Estimating fatigue curves with the random fatigue-limit model, Technometrics, 41, 4, 277-290, DOI: 10.2307/1271342

13. Pollak R.D., Palazotto A.N., 2009, A comparison of maximum likelihood models for fatigue strength characterization in materials exhibiting a fatigue limit, Probabilistic Engineering Mechanics, 24, 2, 236-241, DOI: 10.1016/j.probengmech.2008.06.006

14. Sarkani S., Mazzuchi T.A., Lewandowski D., Kinl D.P., 2007, Runout analysis in fatigue investigation, Engineering Fracture Mechanics, 74, 2971-2980. DOI: $10.1016 /$ j.engfracmech.2006.08.026

15. SснÜтz W., 1996, A history of fatigue, Engineering Fracture Mechanics, 54, 2, 263-300, DOI: 10.1016/0013-7944(95)00178-6 
16. Skibicki D., 2007, Experimental verification of fatigue loading nonproportionality model, Journal of Theoretical And Applied Mechanics, 45, 2, 337-348

17. Strzelecki P., Sempruch J., 2012, Experimental verification of the analytical method for estimated S-N curve in limited fatigue life, Materials Science Forum, 726, 11-16, DOI: 10.4028/www.scientific.net/MSF.726.11

18. Strzelecki P., Sempruch J., 2016, Verification of analytical models of the S-N curve within limited fatigue life, Journal of Theoretical and Applied Mechanics, 54, 1, 63, DOI: 10.15632/jtampl.54.1.63

19. Strzelecki P., Tomaszewski T., 2016. Application of Weibull distribution to describe S-N curve with using small number specimens, AIP Conference Proceedings, 1780, 20007, AIP Publishing, DOI: $10.1063 / 1.4965939$

20. Strzelecki P., Tomaszewski T., Sempruch J., 2016, A method for determining a complete S-N curve using maximum likelihood, [In:] 22nd International Conference on Engineering Mechanics, I. Zolotarev and V. Radolf (Edit.), 530-533, Institute of Thermomechanics, Academy of Sciences of the Czech Republic, v.v.i., Prague

21. Szala G., LigaJ B., 2011, Two-Parameter Fatigue Characteristics of Construction Steels and Their Experimental Verification (in Polish), J. Szala (Edit.), Uniwersytet Technologiczno-Przyrodniczy im. J.J. Śniadeckich, Bydgoszcz

22. Szala G., Ligaj B., 2012, Description of cyclic properties of steel in variability conditions of mean values and amplitudes of loading cycles, Materials Science Forum, 726, 69-76, DOI: 10.4028/www.scientific.net/MSF.726.69

23. Tomaszewski T., Sempruch J., 2017, Fatigue life prediction of aluminium profiles for mechanical engineering, Journal of Theoretical and Applied Mechanics, 55, 2, 497-507, DOI: 10.15632/jtampl.55.2.497

24. Weibull W., 1961, Fatigue Testing and Analysis of Results, Oxford, Pergamon Press LTD. 